\title{
CMEARTICLE
}

\section{Approach to chronic cough in children}

Zai Ru $\underline{C h e n g}^{1}$, MMed, MRCPCH, Ying Xian $\underline{C h u a}^{2}$, MMed, MPH, Choon How $\underline{H o w}^{3}$, MMed, FCFP, Yi Hua $\underline{\operatorname{Tan}}^{1}, \mathrm{MMed}, \mathrm{MRCPCH}$

Mrs Soh brought her eight-year-old son Bobby to see you, as she could not find a solution for his cough, which had lasted for six weeks, despite trying various antihistamines. It had started after a short bout of fever and rhinorrhoea. Bobby was heard coughing in the daytime by his teacher and sometimes at night when he slept in the same room with his mother. Bobby was still able to cycle with his family on weekends. He did not complain of breathlessness and was occasionally able to expectorate yellow phlegm. His teacher had written a letter to Mrs Soh, as other parents had voiced a concern about Bobby's coughing episodes in class.

\section{WHAT IS CHRONIC COUGH IN CHILDREN?}

Chronic cough in children is a common reason for healthcare visits and affects between $5 \%$ and $10 \%$ of children in the general population, as estimated based on parental questionnaires. ${ }^{(1)}$ The definition of chronic cough varies among different guidelines. It is defined as a persistent and unremitting cough lasting more than four weeks in the 2020 CHEST consensus statement. ${ }^{(2)}$ The British Thoracic Society guidelines label chronic cough in children as one that lasts beyond eight weeks, while acknowledging the existence of a prolonged subacute cough that lasts between four and eight weeks. ${ }^{(3)}$

\section{HOW RELEVANT IS THIS TO MY PRACTICE?}

An increase in health-seeking behaviour has been observed among parents of children with chronic cough in this new era of heightened vigilance and surveillance amid the ongoing global COVID-19 pandemic. Prolonged respiratory symptoms could result in the child being isolated, with grave economic and psychological consequences for all individuals involved in the child's care. In Singapore, the 'stay home' notices and quarantine periods to reduce transmission risks among patients or contacts with respiratory symptoms result in the coughing child missing school and necessitate last-minute changes in caregivers' routines to accommodate caring for the child at home. Potential loss in work hours, productivity and household income can cause additional stress to the caregivers. The impact on the family dyad, such as increased caregiver stress, falling academic performance and anxiety over missing major events if subjected to repeated rounds of medical leave, make it crucial for a clinician to develop a sound approach for the management of children with chronic cough. In this article, we suggest an approach to a child with chronic cough in the primary care setting, common causes of chronic cough in children, and indications for referral to a paediatric respiratory specialist for further evaluation and investigations.
Table I. Important clinical cues to describe a child's cough.

\begin{tabular}{|c|c|}
\hline Clinical cue & Description \\
\hline Age of symptom onset & Chronological age at cough onset \\
\hline Wet or dry nature & $\begin{array}{l}\text { Assessed through child's spontaneous } \\
\text { cough, asking child to induce a cough or } \\
\text { caregivers' video/audio recordings }\end{array}$ \\
\hline Triggers & $\begin{array}{l}\text { Cough in relation to exercise or emotion. } \\
\text { Any pattern related to change in } \\
\text { home or new school environment, e.g. } \\
\text { cigarette smoke exposure, new pet, } \\
\text { renovation }\end{array}$ \\
\hline Frequency & Number of cough episodes heard per day \\
\hline Timing of cough & Presence of night awakening \\
\hline Accompanying features & $\begin{array}{l}\text { Wheezing, breathlessness, constitutional } \\
\text { symptoms with loss of appetite, loss of } \\
\text { weight and unexplained intermittent fever }\end{array}$ \\
\hline
\end{tabular}

\section{WHAT CAN I DO IN MY PRACTICE? Evaluation of children with chronic cough}

The initial evaluation of children with cough at first presentation entails a thorough clinical history and targeted physical examination to decide whether to render further treatment or provide parental assurance. In this article, we define chronic cough as unremitting cough for more than four weeks, in accordance with the CHEST $2020^{(2)}$ guidelines.

Describing the characteristics of the child's chronic cough is crucial in a busy primary care setting. It includes questions regarding the age of symptom onset; wet or dry nature of the cough; triggers, frequency and timing of the cough; and the presence of accompanying features, as detailed in Table I. Age of onset and duration of symptoms are important considerations. Determining the frequency and progression of the chronic cough helps in assessing whether the child is having episodes of resolving acute cough or has a potentially serious underlying respiratory condition. Often, a child's cough naturally resolves following episodes of upper respiratory tract infections

\footnotetext{
${ }^{1}$ Respiratory Medicine Service, Department of Paediatrics, KK Women's and Children's Hospital, ${ }^{2}$ National University Polyclinics, Pioneer Polyclinic, ${ }^{3} \mathrm{Care}$ and Health Integration Division, Changi General Hospital, Singapore

Correspondence: Dr Cheng Zai Ru, Staff Physician, Respiratory Medicine Service, Department of Paediatrics, KK Women's and Children's Hospital, 100 Bukit Timah Road, Singapore 229899. cheng.zai.ru@kkh.com.sg
} 
Table II. Key red flag features in history and physical examination findings (adapted from CHEST Guidelines 2020).(2)

\begin{tabular}{|c|c|}
\hline Key red flags & Possible aetiology \\
\hline \multicolumn{2}{|l|}{ History } \\
\hline Chest pain & Arrythmia, asthma, pleuritic, functional \\
\hline Choking & Foreign body inhalation \\
\hline Dyspnoea or tachypnoea & $\begin{array}{l}\text { Compromised lung function, or any chronic lung or cardiac } \\
\text { disease }\end{array}$ \\
\hline Daily wet or productive cough & $\begin{array}{l}\text { Protracted bacterial bronchitis, suppurative lung disease, } \\
\text { recurrent aspiration, atypical infections, TB }\end{array}$ \\
\hline Exertional dyspnoea & Any airway or parenchymal disease \\
\hline Facial pain/purulent nasal discharge & Chronic sinusitis, ciliary dyskinesia \\
\hline Feeding difficulties/irritability and arching after feeds & Any serious systemic or pulmonary illness, aspiration lung disease \\
\hline Hoarse voice/stridor & Laryngeal cleft/problems, airway abnormalities \\
\hline Haemoptysis & Suppurative lung disease, vascular abnormalities \\
\hline Recurrent infections & Immunodeficiency \\
\hline $\begin{array}{l}\text { Previous history of chronic lung or oesophageal disease } \\
\text { (e.g. neonatal lung disease, oesophageal atresia) }\end{array}$ & $\begin{array}{l}\text { Consider complications (e.g. H-type tracheoesophageal fistula, } \\
\text { bronchiectasis, aspiration, asthma) }\end{array}$ \\
\hline \multicolumn{2}{|l|}{ Physical examination } \\
\hline Auscultatory findings & $\begin{array}{l}\text {-Wheeze: asthma, bronchitis, bronchiolitis obliterans, foreign } \\
\text { body aspiration, airway malacia or stenosis, vascular rings, } \\
\text { lymphadenopathy, mediastinal tumours; TB } \\
\text { - Crepitations: any airway disease, parenchymal damage from } \\
\text { interstitial lung disease }\end{array}$ \\
\hline Deformity of chest wall & Any chronic lung disease \\
\hline Digital clubbing & Suppurative lung disease \\
\hline Growth failure & Any serious systemic or pulmonary illness \\
\hline Hypoxia or cyanosis & Any airway or parenchymal disease, cardiac disease \\
\hline Neurodevelopmental abnormality & Aspiration lung disease \\
\hline
\end{tabular}

TB: tuberculosis

(URTIs). However, re-evaluation must be performed for serious underlying conditions in children who have unremitting cough lasting more than four weeks. Timely intervention can limit the progressive damage and burden associated with conditions such as bronchiectasis, aspiration lung disease and foreign body inhalation.

Young children are usually unable to expectorate; hence, using the term 'productive' or 'non-productive' for sputum is not as useful as the term 'wet' or 'dry'. If the caregivers' report about the nature of the cough is unclear, asking the child to induce a cough to demonstrate how the cough sounds during a consult can allow this important clinical question to be answered with more certainty. The caregiver can also be tasked to take video recordings of the child coughing if the child is unable to perform a cough manoeuvre in the clinic. A targeted respiratory examination, especially one that looks for digital clubbing, hyperinflated chest, Harrison sulci and adventitious breath sounds, can guide further evaluation in a child with chronic cough.

Three overlapping categories can be used in the approach to a child with chronic cough:

- 'Normal' child with recurrent episodes of acute cough from upper respiratory tract infections

- Child with chronic dry cough (e.g. somatic cough syndrome, upper airway cough syndrome)
- $\quad$ Child with key red flag features (e.g. bronchiectasis, protracted bacterial bronchitis, tuberculosis [TB], asthma)

These three categories can show considerable overlap, as symptoms can evolve and a child's history can encompass more than one category at various time points. It is important to be mindful of the chronology of events and elicit the key red flag features listed in Table II in the clinical assessment of a child's chronic cough during each visit.

\section{Evaluation of normal children with recurrent episodes of acute cough}

The approach to a child with chronic cough and no red flags is summarised in Fig. 1. A generally healthy child can have as many as eight URTIs annually, with more episodes observed in those who have recently started childcare or preschool. This frequency is reduced in older school-going children, who still experience at least three URTIs in a year on average. ${ }^{(4)}$ Coughs related to URTIs resolve within 1-3 weeks in at least $90 \%$ of children. ${ }^{(5)}$ The parent can be reassured if the cough gradually abates by the third week to become dry-sounding, with cough-free periods of at least a few weeks in between episodes and normal examination findings. Further investigations are not necessary, especially in a well-thriving child who does not show any symptoms during sleep or physical activity on subsequent review. 


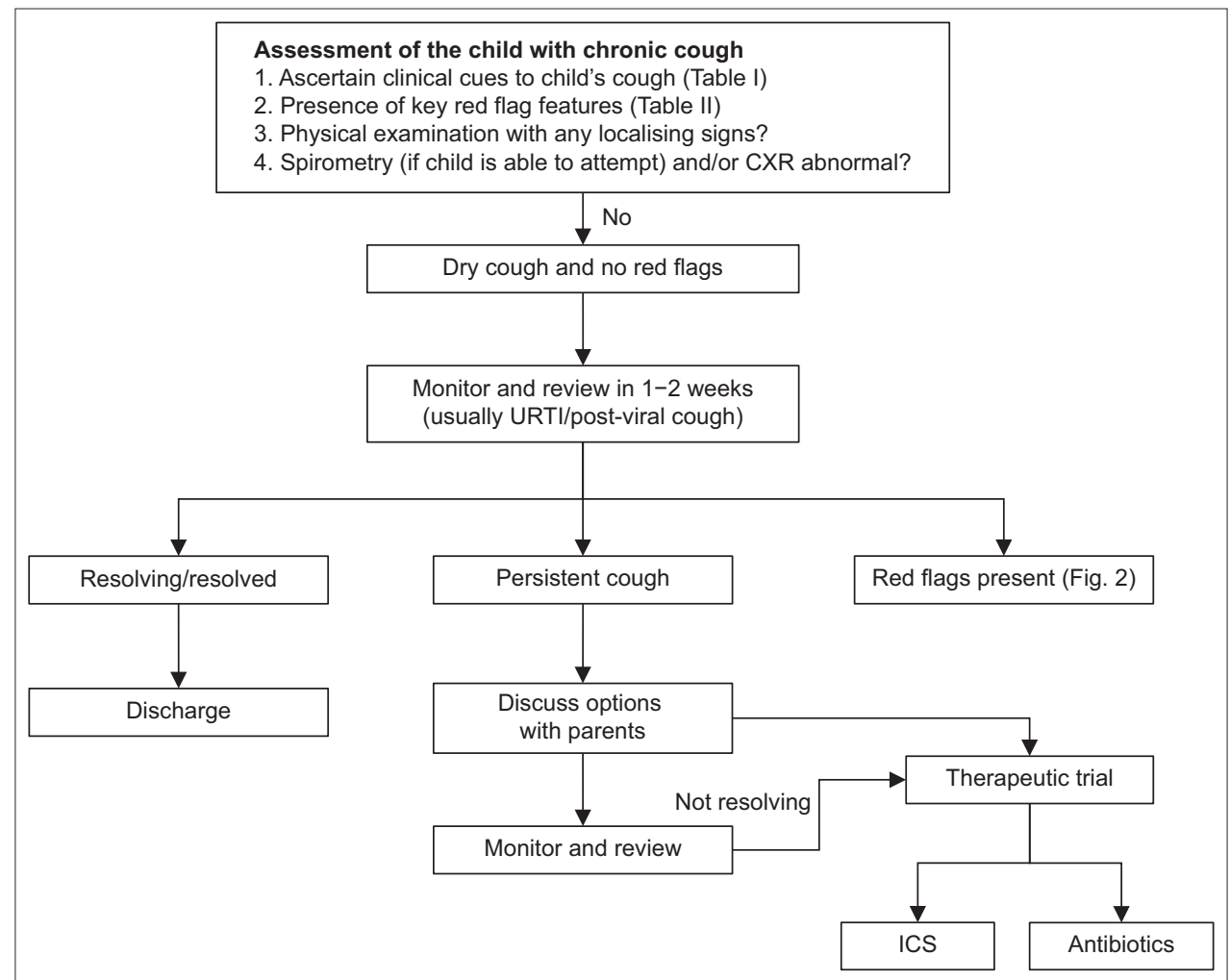

Fig. 1 Flowchart shows approach to child with chronic cough and no red flags. CXR: chest radiography; ICS: inhaled corticosteroids; URTI: upper respiratory tract infection

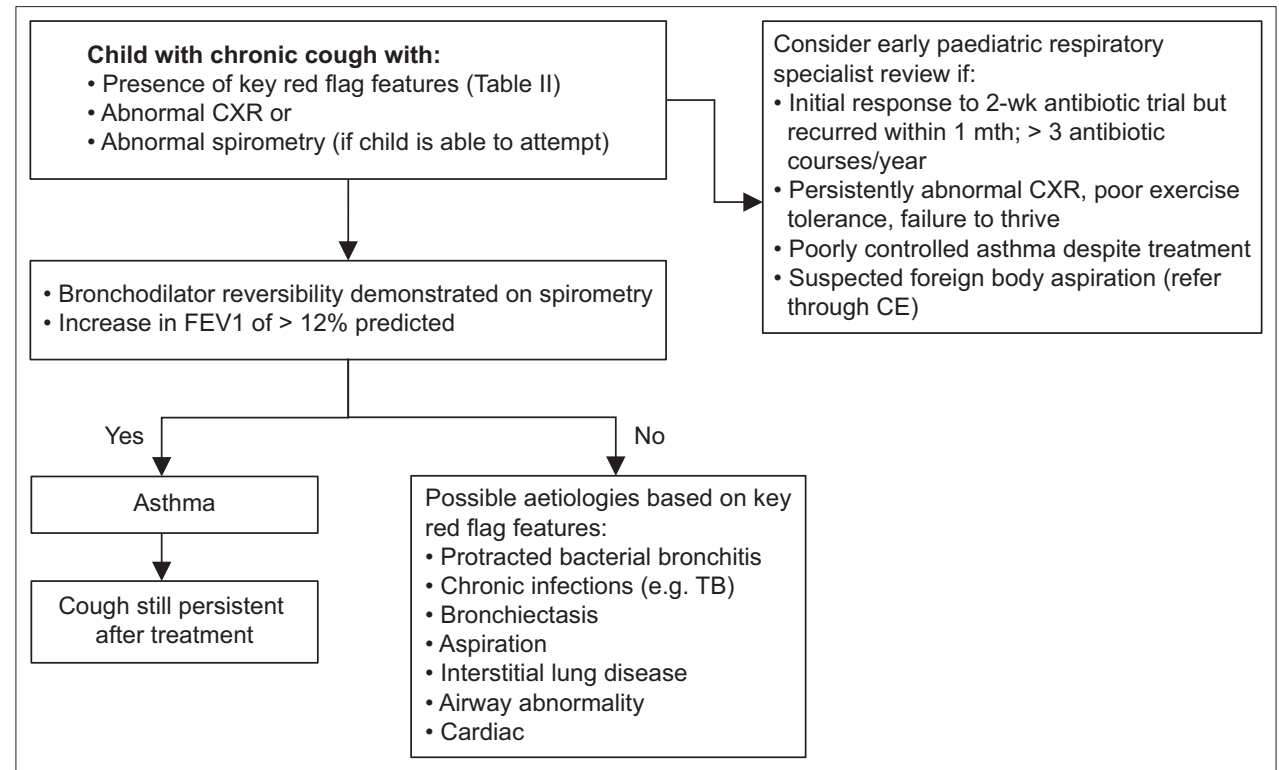

Fig. 2 Flowchart shows approach to child with chronic cough and red flags. CE: Children's Emergency; CXR: chest radiography; FEV1: forced expiratory volume in 1 second; TB: tuberculosis

\section{Children with key red flag features that warrant specialist referral}

Fig. 2 lists the approach to a child with chronic cough and red flags. Specific red flag features help to identify the aetiology of the chronic cough. Attempts should be made to identify these features based on the caregivers' history and after a careful physical examination. For example, the presence of a persistent daily wet cough is always pathological, pointing towards excessive airway secretions, and is most useful in predicting the aetiology. Daily wet cough as a key red flag feature, among others outlined in
Table II, can suggest a possible underlying cause of the child's chronic cough.

Initial investigations include chest radiography (CXR) and spirometry. In a study by Marchant et al, ${ }^{(6)}$ the use of CXR and spirometry in children with chronic cough had specificities of $93 \%$ and $94 \%$ respectively, and abnormal findings were highly indicative of disease. However, these two modalities had low sensitivities of $19 \%$ and $17 \%$, respectively; hence, further investigations are necessary even in a normal CXR or spirometry result if the cough persists with key red flag features. Spirometry 
can be attempted in a child by the age of five years, and bronchodilator response demonstrated by an increase in forced expiratory volume in one second (FEV1) of $>12 \%$ predicted is suggestive of uncontrolled asthma. ${ }^{(7)}$

Upon specialist referral, consideration for non-routine tests should be individualised to the child. These include skin prick tests to establish atopic status, tuberculin skin test (TST) to check for TB infection, flexible bronchoscopy for airway evaluation, bronchoalveolar lavage (BAL) to obtain a microbiological diagnosis, especially in a young child who cannot expectorate, and computed tomography $(\mathrm{CT})$ imaging of the thorax to evaluate lung parenchymal changes. These tests can be performed based on the child's symptoms, clinical assessment and available resources. For example, consideration of flexible bronchoscopy and BAL typically entails one of the following indications: suspicion of airway abnormality or inhaled foreign body, persistently abnormal CXR, and evaluation of aspiration lung disease and lavage for microbiological and cellularity purposes.

The following aetiologies should be considered in children who have chronic cough with key red flag features pointing to a potential underlying cause. Any trial of therapy for the presumed aetiology of a child's chronic cough requires a review 2-4 weeks after therapy to determine whether the appropriate response has been achieved.

\section{Asthma}

Asthma is a condition diagnosed clinically, with no gold standard test for young children, and is characterised as a highly heterogenous and time-variable disease. It affects about $20 \%$ of school-going children in Singapore. It is well accepted that most children with asthma will present with cough during exacerbations, among other symptoms of shortness of breath, wheezing, chest tightness, or symptoms that worsen with exercise or extreme emotion. In a child with isolated cough, caution must be exercised in diagnosing asthma based on cough as the sole presenting symptom. Typical asthma symptoms of wheeze and exertional dyspnoea may not be recognised or initially reported by caregivers and must be actively sought for during each review.

The supporting evidence for establishing a diagnosis of asthma is stronger in the presence of the following conditions: bronchodilator response documented clinically or through parental observation, spirometry results demonstrating significant bronchodilator reversibility and achievement of control based on past treatment with inhaled corticosteroids (ICS) and relief with bronchodilator therapy. Primary care providers can consider a trial of ICS in paediatric patients with suspected asthma. However, overprescription of ICS in a non-atopic child with a prolonged viral infection should be avoided. With the next episode of viral infection, an escalation in the ICS dosage usually results in diminishing returns, and ICS should be stopped in a non-responder who does not exhibit supporting signs and symptoms of asthma.

Awareness of the child's atopic status is useful to convince parents to acknowledge and explore environmental triggers. Lack of physical activity and prolonged containment in homes where environmental triggers persist, including cigarette smoke and exposure to house dust mites, can contribute greatly to disease burden. Objective assessment with spirometry helps to establish evidence for the need for sustained treatment with preventer therapy or determine whether escalation of preventer therapy is required. If symptom control continues to be poor after initiation of bronchodilator and ICS treatment, adherence to therapy and correct inhalational technique must be ascertained. A specialist referral should be considered when the child has persistent symptoms despite adherence to adequate therapy.

In reference to Global Initiative for Asthma guidelines published in March 2020, in view of the COVID-19 pandemic, all tests involving forced expiratory manoeuvres such as spirometry and the use of peak flow meters were temporarily suspended. ${ }^{(7)}$ In the management of acute asthma, nebulisers are avoided where possible, as they may transmit respiratory viral particles for approximately $1 \mathrm{~m}$, and have been replaced with metered dose inhalers and spacer use, with an appropriately sized face mask, if required. Conducting spirometry in a single room with the respiratory technologist in personal protective equipment and protocols for disinfection between patients have now become the norm. In the resumption of these procedures in the outpatient setting, utmost care continues to be taken in ensuring strict infection control, as the role of spirometry is essential in the diagnosis and management of asthma.

\section{Persistent bacterial bronchitis}

An isolated chronic wet cough lasting for at least four weeks, responding to at least two weeks of oral antibiotics, is often attributed to a clinical entity termed persistent or protracted bacterial bronchitis (PBB), in the absence of signs pointing to other causes of productive cough. ${ }^{(8)}$ The common isolated bacterial organisms found in the respiratory tract of children with chronic wet cough were Haemophilus influenzae (28\%-58\%), Streptococcus pneumoniae (13\%-58\%) and Moraxella catarrhalis $(17 \%-59 \%){ }^{(9)}$ An antibiotic course comprising amoxicillinclavulanate for at least two weeks that targets these commonest bacterial organisms increases the chances of resolving the child's chronic cough. However, recurrence of chronic cough can often be expected, and one should seek the possibility of underlying bronchiectasis in poor responders to prolonged and repeated courses of antibiotic therapy.

A respiratory specialist referral is warranted in patients being treated clinically for recurrent PBB that requires more than three antibiotic courses per year. ${ }^{(9)}$ These patients who have recurrent PBB following successful antibiotic therapy require a prolonged period of follow-up to plan further investigations and evaluate factors for relapse. ${ }^{(10)}$ There is a possibility of failure to respond to complete antibiotic course or other causes of chronic wet cough, such as primary ciliary dyskinesia or a child with immunodeficiency. Gaps in knowledge still exist on the optimal management route for children with recurrent PBB, especially in the role of prophylactic antibiotics in preventing recurrence and contribution towards antimicrobial resistance in this group of patients. 


\section{Tuberculosis}

Delayed diagnosis of TB in a child with chronic cough can have devastating consequences for the child, family and community. The local Ministry of Health Clinical Practice Guidelines on TB recommend considering investigating a child for TB if the cough is unremitting at the two-week mark in the presence of objective weight loss and fatigue. ${ }^{(11)}$ The clinician should have heightened suspicion for TB in vulnerable patients with chronic cough who may have inadvertently or unknowingly been exposed to TB in a healthcare setting or within our TB-prevalent community, such as in children with recently acquired latent TB; failure to thrive; or underlying medical conditions such as diabetes mellitus, renal failure and malignancies; or those on immunomodulator medications or chemotherapy. In children below two years of age who are suspected of having TB, the TST is the preferred mode of initial immunological investigation; in those aged two years or older, an interferon-gamma release assay (IGRA) blood test or TST can be used. The IGRA is preferred in young children who have had the Bacillus Calmette-Guérin vaccine to avoid a false-positive TST or in those who are unlikely to return for a TST to be read. ${ }^{(12)}$ A negative TST or IGRA TB test does not rule out a diagnosis of TB. Sputum samples for acid-fast bacilli smear should be obtained and culturing should be performed to confirm the diagnosis and further guide the choice of antimicrobial therapy.

\section{Bronchiectasis}

Bronchiectasis is defined by abnormal dilatation and distortion of airway structures, resulting in chronic airway inflammation and repeated episodes of respiratory tract infections. ${ }^{(13)}$ Chronic impaired mucociliary clearance and concomitant bacterial colonisation associated with dysregulated inflammatory responses result in lung injury. This might be attributable to multiple pathophysiological triggers, including genetic, structural and systemic causes. Primary care providers need to be aware of the various causes of non-cystic fibrosis bronchiectasis in children, such as infections, immunodeficiencies, recurrent aspiration and primary ciliary dyskinesia, so that they can perform a detailed review to look for more key red flag features. This condition mainly presents as prolonged wet or productive cough with persistent unexplained lung crepitations, haemoptysis, partial resolution of severe pneumonia or recurrent episodes of lower respiratory tract infections. In the advanced phase, exertional dyspnoea, fatigue, digital clubbing, chest wall deformity and failure to thrive set in. These symptoms, coupled with CT imaging changes showing dilated broncho-arterial ratio of more than $0.8,{ }^{(14)}$ dilated and thick-walled bronchi seen at the lung periphery, and 'signet-ring' lesions showing dilated lucencies adjacent to the accompanying pulmonary artery branch, establish the diagnosis of bronchiectasis in children. Determining the root cause of bronchiectasis guides management in a tertiary hospital and aids in limiting the cycles of lung injury.

\section{Children with chronic dry cough}

A child with chronic dry cough not associated with any specific key red flag features (Table II) generally has normal
CXR and spirometry results. Potential causes of chronic dry cough are somatic cough syndrome and upper airway cough syndrome.

\section{Somatic cough syndrome}

The term 'somatic cough syndrome'(15) has been used to replace the term 'psychogenic cough', according to Diagnostic and Statistical Manual of Mental Disorders, 5th edition, recommendations. The criteria for diagnosis include the following: (a) one or more somatic symptoms that are disruptive to day-to-day functioning; (b) overwhelming thoughts about the severity of symptoms; (c) constant worry about health or symptoms; (d) excessive time and energy spent on health concerns and symptoms; and (e) symptoms that are unabated for more than six months. Non-pharmacological measures with parental reassurance and/or psychological therapy can help support and provide coping strategies to children and their family.

\section{Upper airway cough syndrome}

Upper airway cough syndrome replaces the previously known entity of postnasal drip cough, which is commonly associated with allergic rhinitis. ${ }^{(16)}$ Symptoms include day and night cough, nasal congestion, rhinorrhoea and frequent throatclearing sounds associated with an itchy throat. A characteristic cobblestone appearance of the posterior oropharyngeal space indicates chronic postnasal drip. Facial tenderness with purulent nasal discharge prompts a diagnosis of sinusitis. Primary care providers can consider a trial of non-sedative antihistamines, intranasal corticosteroids and nasal washings as a first-line treatment, in the absence of key red flag features. These medications when used in combination can bring about an improvement in the chronic cough after 2-4 weeks and should be continued for a longer period of time to effectively treat upper airway cough syndrome. Further investigations with CXR and spirometry are usually not indicated if the child responds to the treatment.

\section{WHEN SHOULD I REFER TO A SPECIALIST?}

For a child with unremitting chronic cough, a referral to a specialist is warranted when the key red flag features from Table II are observed in a child's history and examination, and significantly point towards an underlying aetiology in a child with chronic cough. Figs. 1 and 2 summarise the suggested algorithm in the approach to a child with chronic cough, depending on the presence of key red flag features.

A child can present to the primary care provider at any stage of illness, and it is challenging to categorise his/her diagnosis in a cough category, as signs and symptoms can overlap among different causes. Furthermore, the child's clinical status usually continues to evolve with subsequent reviews. This article serves as a guide to highlight key red flag cough features to help with decision-making for referral and further investigations, but it is non-exhaustive. Understanding the family's ideas, concerns and expectations through a discussion with a consistent caregiver 
and close follow-up of the child remain vital in justifying the next course of action in the management of a child with chronic cough.

\section{TAKE HOME MESSAGES}

1. Key red flag features from history and physical examination can help to indicate the possible aetiology of the cough in the child with chronic cough.

2. CXR and spirometry are useful first-line diagnostic investigations in the evaluation of a child with chronic cough and associated red flag features, or children who do not respond to initial treatment.

3. Any trial of therapy for the presumed aetiology of a child's chronic cough requires a review 2-4 weeks after therapy to determine whether the appropriate response has been achieved.

4. Non-responders should not be subjected to unnecessary escalation in therapy and should instead undergo further evaluation for other causes of chronic cough.

History-taking revealed that Bobby's cough had been unremitting for the past six weeks, and he had been afebrile throughout. He had no personal or family history of atopy and no previous trial of antibiotics. Bobby had no spontaneous cough, but when asked to induce a cough, it sounded wet. Respiratory examination was unremarkable. Chest radiography yielded normal results. You explained the likely diagnosis of protracted bacterial bronchitis to a distressed Mrs Soh and prescribed a two-week course of oral amoxicillin-clavulanate. At follow-up two weeks later, Mrs Soh reported that Bobby's cough had completely resolved. She was immensely grateful for your help, and Bobby was able to return to class without further issues.

\section{ACKNOWLEDGEMENT}

We would like to thank A/Prof Teoh Oon Hoe, Head and Senior Consultant, Paediatric Respiratory Medicine Service, KK Women's and Children's Hospital, Singapore, for providing his invaluable guidance for this manuscript.

\section{REFERENCES}

1. Faniran AO, Peat JK, Woolcock AJ. Measuring persistent cough in children in epidemiological studies: development of a questionnaire and assessment of prevalence in two countries. Chest 1999; 115:434-9.

2. Chang AB, Oppenheimer JJ, Irwin RS; CHEST Expert Cough Panel. Managing chronic cough as a symptom in children and management algorithms. CHEST guideline and expert panel report. Chest 2020; 158:303-29.

3. Shields MD, Bush A, Everard ML, McKenzie S, Primhak R; British Thoracic Society Cough Guideline Group. BTS guidelines: recommendations for the assessment and management of cough in children. Thorax 2008; 63 Suppl 3:iii $1-15$.

4. Weintraub B. Upper respiratory tract infections. Paediatr Rev 2015; 36:554-6.

5. Srivastava A, Bhatt J. Management of childhood cough. Br J Fam Med 2014; 2:24-8.

6. Marchant JM, Masters IB, Taylor SM, Chang AB. Utility of signs and symptoms of chronic cough in predicting specific cause in children. Thorax 2006; 61:694-8.

7. Global Initiative for Asthma. Global Strategy for Asthma Management and Prevention, 2020. Available at: https://ginasthma.org/wp-content/ uploads/2020/04/GINA-2020-full-report_-final-_wms.pdf. Accessed December $22,2020$.

8. Das S, Sockrider M. Protracted bacterial bronchitis (PBB) in children. Am J Respir Crit Care Med 2018; 198:P11-2.

9. Kantar A, Chang AB, Shields MD, et al. ERS statement on protracted bacterial bronchitis in children. Eur Respir J 2017; 50:1602139.

10. Bush A. Persistent bacterial bronchitis: time to venture beyond the umbrella. Front Pediatr 2017; 5:264

11. Ministry of Health Singapore. Prevention, diagnosis and management of tuberculosis. MOH Clinical Practice Guidelines 1/2016. Available at: https:// www.moh.gov.sg/docs/librariesprovider4/guidelines/moh-tb-cpg-full-versionfor-website.pdf. Accessed December 22, 2020.

12. American Academy of Pediatrics. Tuberculosis. In: Kimberlin DW, Brady MT, Jackson MA, Long SS, eds. Red Book (2018): Report of the Committee on Infectious Diseases. $31^{\text {st }}$ ed. Illinois: American Academy of Pediatrics, 2015: 829-853.

13. Goyal V, Grimwood K, Marchant J, Masters IB, Chang AB. Pediatric bronchiectasis: no longer an orphan disease. Pediatr Pulmonol 2016; 51:450-69.

14. Kapur N, Masel JP, Watson D, Masters IB, Chang AB. Bronchoarterial ratio on high-resolution CT scan of the chest in children without pulmonary pathology: need to redefine bronchial dilatation. Chest 2011; 139:1445-50.

15. Vertigan AE, Murad MH, Pringsheim T, et al; CHEST Expert Cough Panel. Somatic Cough Syndrome (Previously Referred to as Psychogenic Cough) and Tic Cough (Previously Referred to as Habit Cough) in Adults and Children: CHEST Guideline and Expert Panel Report. Chest 2015; 148:24-31.

16. Poulose V, Tiew PY, How CH. Approaching chronic cough. Singapore Med J 2016; 57:60-3. 


\section{SINGAPORE MEDICAL COUNCIL CATEGORY 3B CME PROGRAMME} (Code SMJ 202110A)

1. Chronic cough in children is defined in this article as a cough that lasts for more than four weeks.

2. Chronic cough affects the child alone, with no impact on family or social considerations.

3. A school-going child with unremitting cough for more than four weeks accompanied by loss of weight and poor exercise tolerance is most likely having recurrent upper respiratory tract infection and does not need re-evaluation.

4. Young children usually cannot expectorate; hence, it is important to have a child induce a cough during the consultation to characterise whether it is wet or dry.

5. The presence of digital clubbing, hyperinflated chest and Harrison sulci warrants specialist referral for further evaluation.

6. A generally healthy pre-schooler can have as many as eight upper respiratory tract infections annually.

7. If a child's cough gradually abates by the third week to become dry, with cough-free periods of at least a few weeks in between recurrent episodes, has normal growth and physical examination findings, and good exercise tolerance, a referral to a specialist is warranted.

8. Persistent daily wet cough is always pathological and indicates excessive airway secretions.

9. Initial investigations in a child with chronic cough include chest radiography and spirometry, if possible.

10. Spirometry can be attempted in a three-year-old child.

11. Computed tomography $(\mathrm{CT})$ of the thorax is a useful investigation in a child with unremitting cough if it is clinically indicated based on a child's symptoms, clinical assessment and available resources.

12. Asthma affects $40 \%$ of school-going children in Singapore.

13. Typical asthma symptoms of wheeze and exertional dyspnoea may not be recognised or initially reported by caregivers and must be actively sought for during each review.

14. If a child has asthma that does not respond to inhaled corticosteroids, with poor symptom control despite adherence to therapy, it is prudent to refer him/her for specialist evaluation.

15. A specialist referral is warranted for a child being treated for recurrent protracted bacterial bronchitis who requires more than three antibiotic courses a year.

16. In children aged below two years who are suspected of having tuberculosis, the tuberculin skin test is the preferred mode of initial immunological investigation.

17. The diagnosis of bronchiectasis can usually be made clinically and does not require CT imaging.

18. Treatment of somatic cough syndrome mainly involves the use of cough syrups for symptom relief.

19. Upper airway cough syndrome is associated with nasal congestion, rhinorrhoea and a cobblestone appearance of the posterior oropharynx.

20. Any trial of therapy for the presumed aetiology of a child's chronic cough requires a review 2-4 weeks after therapy to decide whether the appropriate response has been achieved.

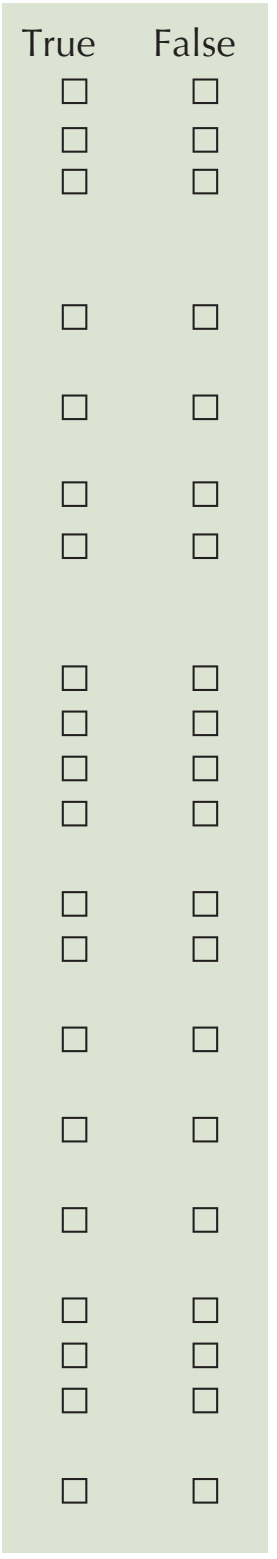

\section{Doctor's particulars:}

Name in full:

MCR no:

Specialty:

Email:

\section{SUBMISSION INSTRUCTIONS}

Visit the SMJ website: http://www.smj.org.sg/current-issue and select the appropriate quiz. You will be redirected to the SMA login page.

For SMA member: (1) Log in with your username and password (if you do not know your password, please click on 'Forgot your password?'). (2) Select your answers for each quiz and click 'Submit'.

For non-SMA member: (1) Create an SMJ CME account or log in with your SMJ CME username and password (for returning users). (2) Make payment of SGD 21.40 (inclusive of $7 \%$ GST) via PayPal to access this month's quizzes. (3) Select your answers for each quiz and click 'Submit'.

RESULTS

(1) Answers will be published online in the SMJ December 2021 issue. (2) The MCR numbers of successful candidates will be posted online at the SMJ website by 31 Decembe 2021. (3) Passing mark is $60 \%$. No mark will be deducted for incorrect answers. (4) The SMJ editorial office will submit the list of successful candidates to the Singapore Medical Council. (5) One CME point is awarded for successful candidates. (6) SMC credits CME points according to the month of publication of the CME article (i.e. points awarded for a quiz published in the October 2021 issue will be credited for the month of October 2021, even if the deadline is in December 2021).

Deadline for submission (October 2021 SMJ 3B CME programme): 12 noon, 24 December 2021. 